there seems sufficient justification for the authors' interpretation of the available statistics that sexual maturity is reached at the end of the second year, at lengths already stated for each species. No definite method for determining the age of whales, beyond the early stages, has emerged, though various studies have been made in this direction, but these have not advanced beyond the stage of fixing that the whale is either an old or a young one, for example, by the number of old scars on the skin, the condition of the vertebral epiphyses, and the number of old corpora lutea.

The application of the results obtained to economic conditions is discussed at some length, but as this necessitates a thorough understanding of the whole stock of whales, the question will have to be considered from all points of view. The arguments put forward by the authors refer to the particular areas in which the investigations were made, and rest largely on the assumption that there is little discrimination in the killing of the whales in any particular area, and that the nature and composition of the catches are likely to be fairly representative of the whale population. The problem of fluctuations in the number and condition of whales requires a lengthy series of observations, but several interesting points are touched upon in the present report which, with a fuller knowledge, may prove to be of great importance. Much is made of the concentration of whales in the area of the Falkland Islands, and some of the causes for this concentration are given considerable prominence, but there are a few million square miles of sea round the antarctic barrier still unexplored, and it may well be that other features will emerge which will call for intensive study. In the history of whaling operations in the northern hemisphere, it has been impressed on us that the locus operandi has shifted from one locality to another, and that in each case the killing off of the whales almost to extinction in any particular region has not been followed by a return to the region of the same type of whales in numbers sufficient to resuscitate the industry. This is, meantime, an unexplainable point, but one that requires attention.

The fifth part is a purely scientific report by Dr. H. A. Baylis and deals with the first consignment of material belonging to the parasitic Nematoda and Acanthocephala collected from whales, seals, and fishes. Five species of Nematoda and three of Acanthocephala are described as new to science. These are interesting from the point of view of the distribution of their hosts.

Another section by Mr. L. H. Matthews is on the birds of South Georgia. Thirty-one species are listed as having been observed at the island both by himself and by previous observers. The text is in the form of brief notes on the species, except in a few cases, for example, the Albatrosses, where the breeding habits are described from the writer's original observations. In most cases a popular name is given to the species, but one misses familiar terms like Night Hawk for the Cape Hen, Paddy for the Sheathbill, Nellie for the Giant Petrel, and Johnny for the Gentoo Penguin. Nineteen species were observed nesting, while other six are quoted from previous observers as breeding on the island. Fregetta is recorded as being observed only by the Transit of Venus Expedition at Royal Bay, but the scientific members of the Endurance Expedition observed a pair of these birds at close range at Larsen Harbour in November 1914. The report opens with a curious mistake as to Shackleton's itinerary on the famous boat journey in April and May 1916 from Elephant Island, South Shetlands, erroneously stated here as South Orkneys, which, by the way, has also been overlooked in the list of corrigenda. There are twelve plates (three in colour) attached to the report, and many of the figures are exceedingly good and most useful.

\title{
The New Zealand Earthquake of Feb. 3.
}

\section{By Dr. C. Davison.}

$\mathrm{O}^{\mathrm{s}}$ knowledge of New Zealand earthquakes extends over little more than a hundred years. Since 1814, when missionaries first landed in the islands, there have been four great earthquakesin $1826,1848,1855$, and 1929 -but none of these, unless it be the earthquake of 1855 , can be compared with the shock that on Feb. 3 brought ruin to Napier and other towns in the North Island. Certainly none has been so destructive of life. On June 17, 1929, 17 persons were killed during the Murchison earthquake; in all previous earthquakes since 1848, not more than seven. During the shock of last week, at least 140 lives were lost, and the number may be increased when the ruins of the larger buildings have been searched.

The earthquake occurred at 10.48 A.M. and lasted for about two minutes. The principal towns damaged are Napier and Hastings. Napier lies on the shore of Hawke Bay, and the houses that suffered most are those in the business quarter, built for the most part on land reclaimed from the sea. Hastings is an inland town about 12 miles south-south-west of Napier. The other places at which buildings are damaged or lives have been lost lie within or near a band about 45 miles long and 12 or 15 miles wide running south-south-west from Napier or parallel to the coast line to Waipukurau. It is in the neighbourhood of Napier, however, that the material damage is greatest. Railway lines there are buckled, roads are fissured, and many landslips have occurred, especially to the north of the town.

The earthquake was recorded at Kew Observatory at 11 h. 6 m. 52 s., P.M. (G.M.T.) on Feb. 2; the amplitudes of the movements were about twice those caused by the earthquake of June 17, 1929, and the total duration of the disturbance was about four hours.

One of the most interesting features of the earthquake is the rise of the land about Napier.

No. 3198, VoL. 127] 
The pool in the harbour known as the Iron Pot, where fishing-boats and small steamers hitherto lay, is now dry land. According to the report of the Governor-General, the bed of the harbour has been raised in places by 18 feet. It seems clear that the rise of the land was not abrupt, for steamers left the harbour and proceeded to sea " on account of the anchorage shallowing rapidly".

For many years, slight earthquakes have been frequent in the Napier district. In the list of New Zealand earthquakes from 1848 to 1890 drawn up by the late Mr. G. Hogben, at least 27 earthquakes had their origins in this zone.

Though the stronger earthquakes of New Zealand can scarcely be ranked with the greatest of some other lands, they have all been accompanied by notable displacements of the earth's crust. In 1826, a cove in the South Island about 80 miles north of Dusky Bay was converted from a safe anchorage for sealing vessels into dry land. The earthquakes of 1848 visited the northern part of the South Island. A great rent was then formed in the mountain chain running south-south-west from Cloudy Bay, and was traced for a distance of
60 miles. During the Wellington earthquake of 1855, a tract of land at the southern end of the North Island measuring 4600 square miles was uplifted from one to nine feet. The fault along which the greatest movement occurred runs along the eastern flank of the Remutaka range, and the nearly vertical scarp was traced for a distance of about 90 miles. Lastly, with the earthquake of 1929, which occurred in the north-west portion of the South Island, the ground on the east side of the White Creek fault was shown, by the renewed levelling of the district, to have risen at one point by $16 \mathrm{ft} .1 \mathrm{in}$.

The investigation of the recent earthquake by the competent seismologists of New Zealand and the re-levelling of its central area can scarcely fail to add greatly to our knowledge. One of the most interesting points to be determined is the connexion of the earthquake with the fault or system of faults that was in action in 1855 ; for though 30 miles or more to the north-north-east of the end of the fault-scarp of that year, the meizoseismal area seems to lie along, or not far from, its line of continuation.

\section{Obituary.}

Mr. A. B. BASSET, F.R.S.

ALFRED BARNARD BASSET was born on I July 25, 1854. He was educated at Trinity College, Cambridge, and graduated in 1877 as 13 th wrangler, a position which could scarcely have represented his real mathematical attainments. He was called to the Bar at Lincoln's Inn in 1879, but not being under the necessity of adopting a profession, he soon abandoned the law, and, apart from the duties of his private station, devoted himself mainly to mathematical research.

From 1883 onwards Basset produced a succession of papers on applied mathematics, mainly on subjects suggested by current discussions. The ' classical ' hydrodynamics had at that time a great fascination for a number of rising mathematicians, and Basset's own contributions in this kind to the Proceedings of the Cambridge Philosophical Society, the London Mathematical Society, and the Philosophical Transactions were of distinct merit. Among the numerous subjects which he treated we may mention the equilibrium of revolving fluids, and the theorems of Dirichlet and Dedekind, the interest in which had been revived by Bryan, Greenhill, and Love. At a later stage he attacked the theory of elastic plates and shells, which was then a matter of controversy, and was led to recognise independently the true explanation of a rather serious difficulty. Mention should also be made of his work on viscosity, and in particular on Boussinesq's problem of the variable slow motion of a sphere in a viscous fluid. These are only a few items out of the long list which appears in the Royal Society's catalogue.

Basset's work was distinguished throughout by a remarkable command of analytical methods. As an example, it may be noted that he was an expert in the use of Bessel functions, and discovered new results in this connexion, at a time when the theory was only beginning to be familiar to English applied mathematicians. He was elected a fellow of the Royal Society in 1889, and was vice-president of the Mathematical Society in 1892-93.

Basset was also the author of several able treatises. A work on hydrodynamics, in which he incorporated much of his original work, was published in 1888, and did much to promote the interest in the subject. This was followed in 1892 by a treatise on physical optics, another of his favourite subjects, to which he devoted immense pains, but which scarcely met with the recognition which it undoubtedly deserved.

At a later period, Basset turned his attention to pure mathematics, and produced two text-books, on cubic and quartic curves, and on solid geometry. But his interest in scientific matters, and his relations with mathematical contemporaries, seem gradually to have faded, partly no doubt owing to failing health, and he lived in great retirement at his seat in Berkshire. He died on Dec. 5, at the age of seventy-six years.

H. L.

\section{Dr. F. M. TURNer.}

Dr. F. M. Turner died unexpectedly on Jan. 17 at the age of sixty-four years, after a surgical operation. Educated at Cambridge and Guy's Hospital, he was for thirty-four years the loved and respected superintendent of the South-Eastern Fever Hospital at New Cross. He was an acute student of infectious diseases, and published notable work on return. cases of scarlet fever in 1906 and on the relation between vaccination and smallpox in Biometrika in 1906 and 1907.

Dr. Turner was a man of insatiable curiosity and had wide interests outside his immediate professional concerns, especially in fresh-water biology and the keeping of aquaria, in which he had a happy

$$
\text { No. 3198, VoL. 127] }
$$

